\title{
Tratamiento informativo de la nueva ley antitabaco en la prensa española
}

\author{
Idoia CAMACHO MARKINA \\ Universidad del País Vasco-UPV/EHU \\ idoia.camacho@ehu.es \\ Alazne AIESTARAn YARZA \\ Universidad del País Vasco-UPV/EHU \\ alazne.aiestaran@ehu.es
}

Recibido: 19/09/2012

Aceptado: 29/01/2013

\begin{abstract}
Resumen
En este artículo se recogen los resultados de una investigación que analiza el tratamiento que dieron los diarios El País, El Mundo, ABC, La Vanguardia y La Razón de la noticia sobre la aprobación de la ley antitabaco del pasado diciembre de 2010. El análisis de contenido -desde el punto de vista del framingde las informaciones y opiniones publicadas sobre el tema a lo largo de seis meses pone de manifiesto que en la mayoría de ellas prevaleció un mensaje contrario a su aprobación, destacando que la norma traería más perjuicios que beneficios a la sociedad española.
\end{abstract}

Palabras clave: ley antitabaco, framing, análisis de contenido, prensa escrita.

\section{News coverage of the smoking ban in the Spanish dailies}

\begin{abstract}
This article presents the results of a study that analyzes the news coverage given by the Spanish dailies El Pais, El Mundo, ABC, La Vanguardia and La Razón to the approval of the new smoking ban in December 2010. The content analysis conducted on the news and opinion articles published on the subject over a six-month period -according to the methodology of framing- shows that in most of the articles the prevailing message was against the smoking ban, noting that the new law would bring more harm than good to the Spanish society.
\end{abstract}

Keywords: smoking ban, framing, content analysis, newspapers.

\section{Referencia normalizada}

CAMACHO MARKINA, Idoia y AIESTARAN YARZA, Alazne (2013): “Tratamiento informativo de la nueva ley antitabaco en la prensa española”. Estudios sobre el Mensaje Periodístico. Vol. 19, Núm. 2 (julio-diciembre), págs.: 649-665. Madrid, Servicio de Publicaciones de la Universidad Complutense.

Sumario: 1. Introducción: tabaquismo y medios de comunicación. 2. Objetivos y metodología. 3. Metodología de análisis; 3.1. Número y tipo de textos; 3.2. Autoría de los textos; 3.3. Ubicación y extensión de los textos; 3.4. Análisis de titulares; 3.5. Tema central; 3.6. Fuentes de información; 3.7. Información gráfica. 4. Conclusiones. 5. Referencias.

\section{Introducción: tabaquismo y medios de comunicación}

En las primeras décadas del siglo XX el consumo mundial de tabaco creció rápidamente, impulsado por las campañas de publicidad difundidas por las grandes empresas tabaqueras en los medios de comunicación. "Los cigarrillos son un producto de la era de los medios masivos de comunicación; el arte y la ciencia de la comunicación masiva, así como el marketing masivo fueron cruciales para el crecimiento del consumo de tabaco en el siglo pasado" (Marcus, 2008: iv).

A partir de 1930 comenzaron a publicarse los primeros estudios acerca de los efectos nocivos del tabaco sobre la salud en revistas médicas y científicas. "Desde enton- 
ces, son multitud los trabajos científicos que demuestran la asociación entre tabaco y cáncer de diferentes localizaciones, arteriosclerosis, cardiopatía isquémica o broncopatía crónica, entre otros" (Serrano, Rojo, 2004: 12).

En los últimos años del siglo XX, las instituciones políticas empezaron a tomar medidas para reducir el impacto del consumo de tabaco entre la población, probada y conocida ya la evidencia de que el hábito de fumar provoca numerosas enfermedades, que a su vez suponen grandes gastos públicos por atención médica y por productividad perdida.

Además de las iniciativas educativas dirigidas a la prevención y al abandono del consumo de tabaco, en las últimas décadas se han incrementado los impuestos al tabaco, se ha restringido el acceso de los jóvenes a los cigarrillos, se ha prohibido su publicidad en los medios de comunicación y en las citas deportivas, y se han aprobado leyes para proteger a los ciudadanos del humo en espacios cerrados.

En el Estado español, en 2005 se aprobó la ley 28/2005, de 26 de diciembre, de medidas sanitarias frente al tabaquismo y reguladora de la venta, el suministro, el consumo y la publicidad de los productos del tabaco. Esta ley constituyó "un avance importante que garantiza el progreso en el ámbito del tratamiento del tabaquismo, en la dirección marcada por los organismos internacionales" (Germán, 2009: 119), ya que tuvo como consecuencia la práctica desaparición de la publicidad directa y la reducción significativa de los niveles de nicotina en la mayoría de espacios públicos, a excepción de aquellos lugares de mayor exposición de la población al humo ambiental del tabaco, como son los lugares de ocio y hostelería.

Sin embargo, la ley fue el origen de numerosas polémicas, principalmente por las discrepancias en su interpretación y su aplicación, y por los problemas que planteó la habilitación de zonas para fumadores en determinados sectores, como la hostelería.

Para resolver dichas controversias, el Gobierno promovió en 2010 una modificación de la ley, cuyo resultado se refleja en la ley 42/2010, de 30 de diciembre, que entró en vigor el 2 de enero de 2011. Esta ley, conocida como nueva ley antitabaco, o ley del tabaco, prohíbe fumar en todos los espacios públicos y termina con las excepciones mantenidas por la ley anterior de 2005, que se demostró ineficaz para conseguir espacios cerrados sin humos.

Al margen de las actuaciones en materia legal, numerosas investigaciones han evidenciado que los medios de comunicación de masas han jugado un papel fundamental en la lucha frente al tabaquismo, anteriormente a llevarse a cabo estas medidas políticas, tal y como nos recuerda Stephen E. Marcus (2008: iv) cuando dice que los medios han contribuido significativamente a disminuir aproximadamente el 50\% el hábito de fumar, lo cual "lograron incrementando el conocimiento público sobre los riesgos del consumo de cigarrillos para la salud, lo que contribuyó a cambiar las normas sociales respecto del consumo de cigarrillos y aumentó la aceptación pública de las políticas de control del tabaco".

También los investigadores Llaguno-Aguilar, Dorantes-Alonso, Thrasher, Villalobos y Besley (2008: 349) subrayan que los medios influyen en las políticas públicas, por lo que pueden ser una herramienta poderosa para promover las políticas en contra de tabaquismo. Según estos autores, en Canadá los medios impresos han tenido más 
impacto que la investigación científica o el discurso político en la adopción de leyes que promovieron áreas libres de humo de tabaco. En Estados Unidos el mayor nivel de cobertura mediática sobre tabaquismo se asocia con un mayor conocimiento de sus daños, una mayor desaprobación del fumar, menor prevalencia del hábito de fumar en bares, menor prevalencia del fumar en jóvenes, y más cambios en las políticas públicas en el ámbito local.

Por su parte, Barrueco (2003: 85) corrobora la importancia de la utilización de medios de comunicación en las estrategias antitabaco, ya que se ha demostrado su utilidad, especialmente en aquellas acciones dirigidas a jóvenes y cuando se llevan a cabo de forma conjunta con otras intervenciones en distintos medios de la comunidad, tales como educación en la escuela, eliminación de la publicidad, restricción del acceso de los menores al tabaco e incremento del precio.

Efectivamente, los medios de comunicación son parte importante de cualquier estrategia de información y educación, ya que tienen la capacidad de acceder a gran parte de la población. Además, la mayoría de los ciudadanos recibe buena parte de su bagaje cultural a través de ellos, por lo que pueden contribuir a la difusión de modelos de vida saludable. Los avances en el campo científico han demostrado que existe una relación directa entre los estilos de vida de las personas y su estado de salud. La información difundida por los medios puede incidir en los comportamientos de los individuos, reforzando los que son adecuados y modificando aquellos que pueden ser perjudiciales para su salud (Camacho, 2009: 828).

En el caso que nos ocupa, pues, concluimos que los mass media pueden ser eficaces para aumentar la concienciación social en contra del consumo de tabaco, de tal manera que contribuyan a prevenir el inicio del hábito de fumar en personas jóvenes y al abandono de dicho hábito en personas que ya lo tienen.

Para que este objetivo sea realidad, es necesario que los periodistas cumplan con una de las funciones de su profesión, que, en palabras de Francisco Cañizares, presidente de la Asociación Nacional de Informadores de la Salud, "consiste en documentarse e investigar a fondo sobre un asunto para poder transmitir a los ciudadanos aquello que es relevante". En el caso de la aprobación de la ley antitabaco, según Cañizares, "lo relevante es destacar que ley que acaba de aprobarse es trascendental para la salud pública porque salvará miles de vidas, no provocará paro en el sector de la hostelería, como pregona la industria tabaquera o sus portavoces "pantalla", y a la larga supondrá un ahorro de miles de millones de euros al sistema sanitario" (ANIS, 2011: 1).

\section{Objetivos y metodología}

Es objetivo de esta investigación analizar el tratamiento informativo que la prensa escrita diaria española hizo acerca de la nueva ley antitabaco, publicada el pasado 31 de diciembre de 2010. Con este análisis pretendemos determinar cuáles son los mensajes que los periódicos transmitieron a la sociedad sobre este tema, desde el punto de vista del framing, esto es, establecer cuáles fueron los encuadres que los medios dieron a esos mensajes: si primó el mensaje médico según el cual la ley es beneficiosa para la sociedad porque fumar es una conducta perjudicial para la salud, o si prevaleció el mensaje de que la nueva ley traería perjuicios para los fumadores y la hostelería. 
La teoría del encuadre o teoría del framing afirma que la percepción que el público tiene de los asuntos sociales está condicionada, en gran parte, por la contribución de los medios de comunicación. Un mayor énfasis mediático sobre un determinado tema o asunto social tiende a provocar en la opinión pública una mayor preocupación sobre ese tema. "Al perfilar significados de la realidad, la noticia y sus frames ofrecen visiones del mundo que el público asume de algún modo, consciente o no del entramado institucional al que se someten los acontecimientos" (Sádaba, 2008: 92).

Los periodistas, como mediadores entre las fuentes que generan noticias y la audiencia a la que las dirigen, otorgan a las informaciones un enfoque o encuadre determinado (frame), es decir, seleccionan una parte de la realidad y se la muestran a su audiencia después de hacerla pasar por los filtros propios del proceso productivo periodístico. Estos filtros o encuadres transforman los acontecimientos en productos informativos, que son los mensajes que finalmente llegan al público. En consecuencia, los medios de comunicación no reflejan la realidad de manera objetiva, sino que ofrecen una imagen fabricada de lo que sucede en el mundo y así contribuyen a construir la realidad social.

La ordenación de las noticias en secciones, su extensión, la página donde se ubican, las fuentes de información, el diseño, los titulares, los géneros, las fotografías... son los recursos informativos que utilizan los periódicos para encuadrar las informaciones, y, dependiendo de qué elementos se elijan, se subrayarán determinados aspectos de los acontecimientos y se obviarán otros.

Dentro de las propias noticias, el análisis de las palabras y construcciones sintácticas que se escogen para elaborar los titulares y los textos permiten medir la carga subjetiva de los diarios con respecto al tema tratado. $Y$ es que la separación entre información y opinión presentada en los manuales de estilo como voz autorizada para diferenciar la objetividad y la subjetividad de los periodistas no lo es tal en la práctica profesional (Teramo, Venino, 2003: 150).

Además, "la relevancia que conceden los medios a ciertos temas o el silencio que guardan sobre otros influye decisivamente en la opinión pública, en la relevancia que esta concede a determinados asuntos y en el modo en cómo piensa acerca de los mismos, dándole una importancia mayor o menor, o enfocándolos en una determinada dirección" (Giménez, Berganza, 2009: 57-58).

Por tanto, el encuadre of frame genera formas diferentes de ver la realidad. Los medios de comunicación dictan implícitamente a los receptores una forma de pensar sobre ciertos asuntos al dar un enfoque determinado a las noticias, por cuanto seleccionan y enfatizan palabras, expresiones e imágenes, para conferir un punto de vista o una perspectiva concreta (Igartua, Muñiz, 2007: 93-94).

La hipótesis de partida de la investigación es que la prensa enfatizó los aspectos negativos de la ley antitabaco, por lo que ofreció un enfoque que contribuyó a aumentar la visión negativa de la población sobre las restricciones al humo del tabaco. Así, los medios no cumplieron con la función de servicio público que se les presupone, que les exige investigar y documentarse sobre lo relevante de los hechos y explicarlo con rigurosidad para que el público disponga de criterios para tomar decisiones. 
Hemos llevado a cabo un análisis diacrónico, para estudiar la cobertura de la ley del tabaco no sólo en el momento en que ésta fue publicada, sino comprobando su evolución a lo largo de un periodo de tiempo. Concretamente, hemos analizado un espacio de seis meses, en torno a la promulgación de la norma, comenzando un mes antes (el 1 de diciembre de 2010) y terminando cinco meses después (el 31 de mayo de 2011, que además es el Día Mundial sin tabaco, por lo que es habitual que se generen noticias sobre el tema en los medios). El análisis de medio año nos ofrece una visión en perspectiva sobre el comportamiento de la prensa ante este hecho noticioso y nos permite estudiar la relevancia que le ha otorgado: si los diarios informaron sólo de manera puntual cuando la ley entró en vigor o si hubo un seguimiento del proceso anterior y de las repercusiones y consecuencias de su aprobación.

Para alcanzar el objetivo propuesto, hemos utilizado el método de análisis de contenido cuantitativo y cualitativo. Tal como explica Báez (2007: 290), "el análisis de contenido cualitativo busca temas, describe sus particularidades, establece las categorías de análisis y los interpreta; y el análisis de contenido cuantitativo se sustenta en el recuento, por lo que el valor o la importancia de los contenidos se establece como resultado de la frecuencia con la que aparecen las palabras, fragmentos de frases o frases enteras, consideradas como unidades informativas o de significación".

El universo objeto de estudio son los diarios de información general españoles publicados durante un mes antes y cinco meses después de la aprobación de la ley antitabaco. La muestra elegida está compuesta por los 179 ejemplares que publicaron durante esos seis meses cada uno de los cinco diarios de ámbito estatal con mayor difusión, según las últimas cifras publicadas por la OJD -correspondientes al periodo enero-diciembre 2011-: El País (promedio de difusión: 365.117 ejemplares), El Mundo (252.770), ABC (221.351), La Vanguardia (190.033) y La Razón (103.789). Es decir, la muestra está formada por un total de 895 periódicos. Hemos analizado las ediciones nacionales de El País, El Mundo y La Razón, la edición regional de Madrid de $A B C$ y la edición de Barcelona de La Vanguardia.

Hemos incluido en el estudio los diarios completos, con todas sus páginas, excluyendo los suplementos y las revistas con numeración independiente que se publican de manera autónoma junto con ellos.

La unidad de análisis del estudio ha sido cada texto publicado en los diarios mencionados (ya sea informativo, interpretativo o de opinión) que gira en torno a la ley del tabaco como único tema o como uno de los temas principales, en los seis meses analizados. En el caso de textos que tratan diferentes asuntos, el método para determinar si la norma es uno de los temas principales ha sido que se haga mención a ella en los elementos de titulación o en los elementos gráficos, porque es a través de estos elementos como los medios enfatizan los aspectos de las informaciones que quieren resaltar.

\section{Resultados}

\subsection{Número y tipo de textos}

A lo largo de los seis meses de estudio, los cinco diarios publicaron un total de 269 piezas periodísticas sobre aspectos relacionados con la ley antitabaco: El País, 43 piezas; El Mundo, 30; ABC, 59; La Vanguardia, 79; y La Razón, 58. El periodo más pro- 
lífico en cuanto a información sobre este tema es el comprendido entre el 2 y el 19 de enero, ambos inclusive. En estas casi tres semanas, en las que todos los días se publicaron textos sobre la ley, se concentra el $50,2 \%$ de los textos publicados en los seis meses (135 piezas). En diciembre se publicó el 12,6\% (34 piezas); entre el 20 y el 31 de enero, el 7,4\% (20); en febrero, el 15,2\% (41); en marzo, el 7,4\% (20); en abril, el $3,3 \%$ (9); y en mayo, el 3,7\% (10).

Estos datos indican que, aunque sí es cierto que el mes anterior y los meses siguientes a la aprobación de la norma se informa sobre cuestiones relacionadas con ella -es decir, hay un cierto seguimiento del tema-, el grueso de las informaciones se concentran en los 18 días posteriores a su aprobación. En el gráfico 1 se aprecia que los cinco diarios han seguido una evolución muy similar en cuanto al número de textos publicados durante los seis meses estudiados.

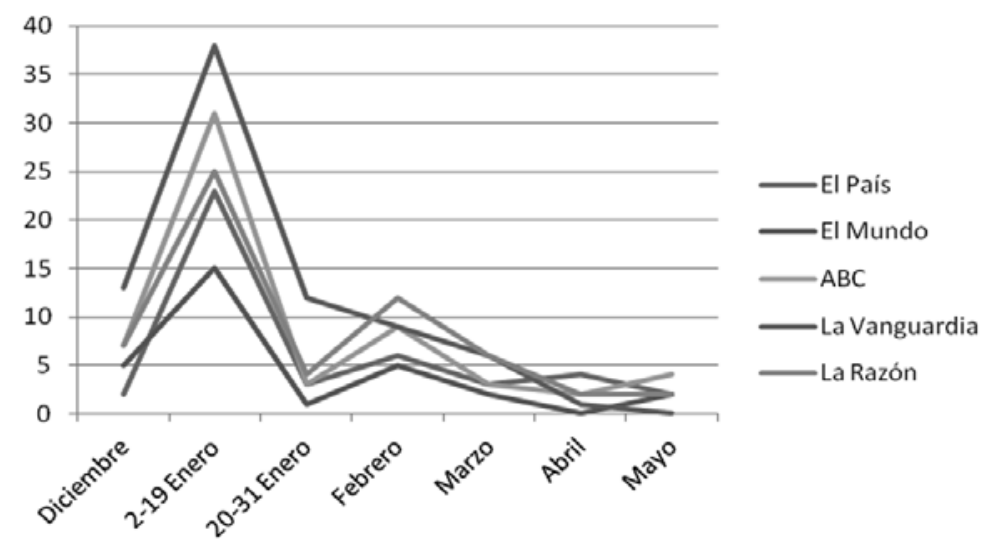

Gráfico 1.- $\mathrm{N}^{\mathrm{o}}$ de textos publicados por fecha, según diarios

En cuanto a los géneros periodísticos utilizados, la mayor parte de piezas corresponden a géneros opinativos $(46,9 \%)$. Dentro de ellos, destacan sobre todo las columnas y comentarios $(18,2 \%)$ y las cartas al director $(16 \%)$. También es reseñable el importante número de editoriales que se dedican a la ley del tabaco $(21$, el $7,8 \%$ de los textos), sobre todo si tenemos en cuenta otro dato que indicaremos más adelante, y es que el tema de la ley tan sólo fue portada en 18 ocasiones. El 33,1\% de las piezas son informativas (noticias o foto-noticias) y el 19,3\% son textos interpretativos (reportajes, entrevistas, crónicas y análisis).

Por tanto, la cobertura de la ley antitabaco se ha tratado desde la perspectiva de un periodismo de opinión, sobre todo, y de un periodismo informativo puro en segundo lugar. Es decir, que los periódicos encuadran la norma en comunicación de opiniones, más que en comunicación de hechos.

Esto significa que, más que a informar sobre las consecuencias en la sociedad de la aprobación de la ley, lo que hacen es -por un lado, y en mayor medida- emitir juicios de valor sobre sus posibles consecuencias, y -por otro lado- ofrecer una visión aséptica del texto de la ley, lo cual indica que el tema, más allá del contenido de la disposición, 
no ha generado demasiada información. Sin embargo, la ley antes de su aprobación ya había creado en la sociedad un clima de debate que se trasladó a los medios y éstos han sabido sacarle rédito resaltando esa controversia que se refleja en los diarios analizados. También es reseñable el bajo porcentaje de géneros de interpretación utilizados, por lo que no ha habido una preocupación por redactar textos elaborados, que profundicen y ofrezcan explicaciones sobre la nueva situación creada por la ley.

$\mathrm{Si}$ analizamos las diferencias entre los cinco diarios, observamos que en todos predomina el estilo eminentemente opinativo, aunque no en la misma proporción. $L a$ Vanguardia es el periódico que más textos de opinión publica (52\% del total de piezas dedicadas al tema estudiado) y El Mundo el que menos textos interpretativos ofrece (3,3\%, una sola crónica). Los otros tres diarios dedican un reparto más equilibrado a los tres tipos de géneros.

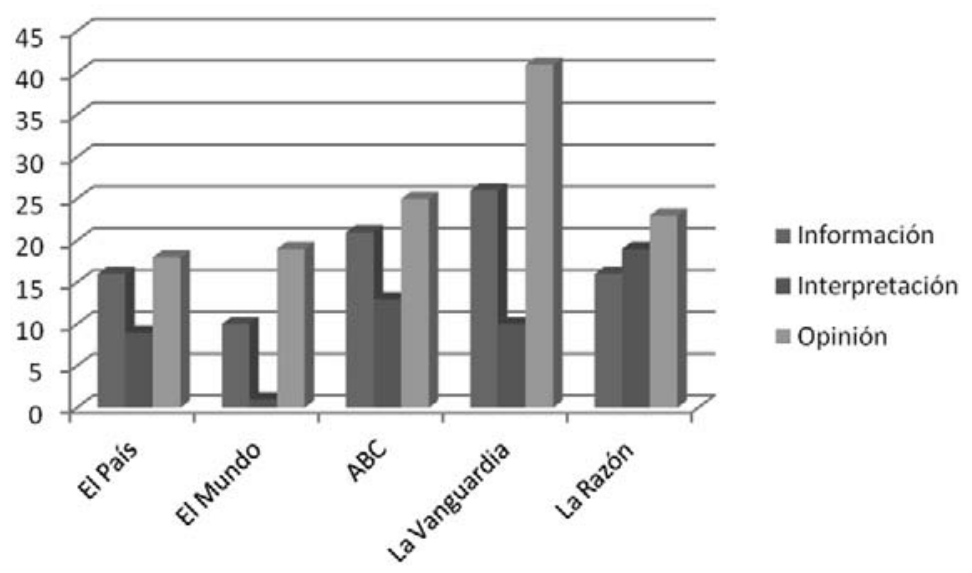

Gráfico 2.- Distribución de los géneros según diarios

\subsection{Autoría de los textos}

En lo que se refiere a la autoría de las piezas analizadas, es reseñable que hay un alto porcentaje de textos firmados por lectores, es decir, de cartas al director (16\%). Este dato indica que el tema de la ley antitabaco ha suscitado interés en la sociedad, lo que se traduce en las numerosas intervenciones generadas en los medios por parte del público receptor de las noticias. También es importante destacar, aunque en este caso en sentido negativo, que sólo un 1,9\% de las piezas están firmadas por expertos colaboradores, que son los que pueden aportar un punto de vista más riguroso y especializado sobre el tema.

La mayoría de los textos aparecen firmados por redactores del diario o colaboradores habituales $(63,2 \%)$. En total, los cinco diarios utilizan 149 periodistas para cubrir el tema de la aprobación de la ley: 44 ABC, 34 El País, 30 La Vanguardia, 22 El Mundo y 19 La Razón.

La gran mayoría de los periodistas y colaboradores habituales $(77,8 \%)$ escriben una única pieza en todo el periodo analizado y un $10,1 \%$ de ellos escriben dos piezas. 
Si tenemos en cuenta únicamente los que elaboran tres o más textos, es decir, los que producen el grueso de las informaciones sobre la ley del tabaco, el número de redactores se reduce a 13 , reflejados en la siguiente tabla.

Tabla 1. Periodistas más prolíficos (con tres o más piezas)

\begin{tabular}{|l|l|l|r|}
\multicolumn{1}{|c|}{ Redactores } & \multicolumn{1}{c|}{ Perfil } & \multicolumn{1}{c|}{ Diario } & No de textos \\
\hline Erik Montalbán & Especializado en temas sociales & La Razón & 17 \\
\hline Celeste López & Especializada en salud & La Vanguardia & 9 \\
\hline Nuria Ramírez de Castro & Especializada en salud & ABC & 6 \\
\hline Jaime Vicente Echagüe & Especializado en temas sociales & La Razón & 5 \\
\hline Sergio Alonso & Especializado en salud & La Razón & 3 \\
\hline Quim Monzó & Columnista & La Vanguardia & 3 \\
\hline Ana Macpherson & Especializada en salud & La Vanguardia & 3 \\
\hline Alicia Rodríguez de Paz & Especializada en temas sociales & La Vanguardia & 3 \\
\hline Fernando J. Pérez & Redacción Málaga & El País & 3 \\
\hline Ferran Balcells & Redacción Barcelona & El País & 3 \\
\hline Jaime Prats & Especializado en salud & El País & 3 \\
\hline Esther Armora & Especializada en salud & ABC & 3 \\
\hline María Isabel Serrano & Especializada en temas sociales & ABC & 3 \\
\hline
\end{tabular}

La gran mayoría de ellos son periodistas especializados en salud o especializados en temas sociales (dentro de los cuales se enmarcan los de salud), es decir, que escriben habitualmente sobre este tema. Este dato es un indicador de que los periódicos han tenido especial cuidado de que los periodistas que escribían sobre la ley antitabaco tuvieran experiencia en temas relacionados con la salud. Los periodistas especializados en salud tienen capacidad "para transmitir eficazmente y asegurar la precisión de la información sociosanitaria que recibe la población general" (Hernández, 2011: 29). Tan solo hay dos que no son redactores especializados, sino que se encargan de cubrir las informaciones sobre su ámbito geográfico correspondiente.

Por otro lado, también hay que mencionar que existe un porcentaje elevado de textos sin firma $(13,8 \%)$ o bajo el tópico Redacción $(4,8 \%)$. Si a la suma de estas dos últimas cifras restamos los editoriales -siempre sin firma-, el resultado es que un 10,8\% de las informaciones son anónimas. Sabemos que los textos anónimos y los firmados por el diario en realidad a menudo son informaciones en las que se oculta que han sido elaboradas por una o varias agencias de noticias, y se publican prácticamente sin ninguna intervención por parte de los periodistas que las escriben (Gelado, 2009: 266267).

\subsection{Ubicación y extensión de los textos}

La mayoría de las informaciones sobre la ley se publican en la sección de 'Sociedad' $(43,5 \%)$, sección que se caracteriza por la heterogeneidad de los temas que recoge. Cuatro de los cinco diarios sitúan el grueso de sus informaciones en esta sección, que en el diario catalán se denomina 'Tendencias' (El País, 65,1\%; La Razón, 50\%; La Vanguardia, 44,3\%; y $A B C, 40,7 \%$ ). El Mundo es el único que opta por un criterio ge- 
ográfico a la hora de ubicar las piezas, ya que sitúa la mayor parte $(43,3 \%)$ en la sección de 'España'.

En segundo lugar, es destacable que una parte importante de los textos se enmarca en la sección de 'Opinión' (38,3\%), aspecto este que hemos desarrollado cuando hemos tratado los géneros utilizados.

El análisis de las portadas pone de manifiesto que, en general, el asunto de la ley no ha recibido especial relevancia por parte de los periódicos, aunque podemos observar desigualdades entre los diferentes medios. Así, La Razón es el que más portadas dedica al tema (8), seguido de El País, El Mundo y La Vanguardia (3), y de $A B C$, con tan solo una portada. Por tanto, la ley antitabaco y todo lo relacionado con ella no ha sido destacado como uno de los temas principales entre la oferta de los periódicos. La poca relevancia que recibe el tema en las portadas se corrobora con el dato de que apenas hay coincidencias en los días en que los diferentes diarios llevan la ley del tabaco a su portada ${ }^{1}$.

Tampoco se otorga al tema una ubicación preferente en el interior de los diarios, ya que tan solo un $31,6 \%$ de los textos se sitúan en páginas impares, que normalmente son las que recogen las noticias a las que los periódicos dan más importancia, porque tienen más probabilidad de ser leídas.

En lo que se refiere a la extensión de las informaciones, hay que señalar que la gran mayoría de ellas ocupa menos de la mitad de una página $(71,7 \%)$, por lo que en general se trata de textos de formato reducido. Los porcentajes referidos al tamaño de las piezas son los siguientes: un $48 \%$ ocupa menos de un cuarto de página, un $23,8 \%$ ocupa entre uno y dos cuartos, un $8,9 \%$ entre dos y tres cuartos, un $4,1 \%$ más de tres cuartos pero menos de una página, un $5,2 \%$ la página completa y un $10 \%$ ocupa más de una página.

\subsection{Análisis de titulares}

Los titulares son un indicativo para saber cómo encuadran la información los diferentes medios de comunicación. Los que utilizan los diarios en las noticias analizadas son de carácter interpretativo más que informativo, es decir, incluyen una valoración del redactor. Esto es lógico, si tenemos en cuenta que ya un mes antes de la aprobación de la norma se van publicando varias piezas que ofrecen informaciones complementarias y opiniones sobre la aprobación de la ley y su posterior aplicación. Así, siendo conocida la noticia principal, los diarios tratan de incluir un toque de originalidad e interpretación en los títulos. Por otro lado, los titulares de los géneros de opinión destacan por su brevedad y su carácter apelativo y/o expresivo.

Los titulares apelativos se caracterizan por utilizar el lenguaje para llamar la atención sobre un hecho del que no se informa en profundidad. A veces tienen el objetivo de reforzar o modificar actitudes de los destinatarios, apelando a su emotividad para despertar sensaciones en ellos. Los titulares expresivos, por su parte, se orientan más a evocar un hecho que se supone conocido por el lector que a informar sobre él. Sue-

1 La Razón publica el tema en portada los días 22 diciembre; 3, 6 ,10 y 29 enero; 12 y 17 de febrero; y 19 marzo. El País: 3 y 10 enero, 24 abril. El Mundo: 4 y 5 enero, 15 febrero. La Vanguardia: 3 y 5 enero, 29 marzo. $A B C: 30$ marzo. 
len ser palabras sueltas, siempre impactantes, que buscan sobre todo reclamar la atención del lector. En ocasiones, tal y como su nombre indica, expresan los sentimientos que la noticia suscita en los lectores (Armentia, Caminos, 2009: 150-151).

Los titulares de las informaciones del mes de diciembre son eminentemente informativos acerca de la aprobación de la disposición y la prohibición de fumar en bares y restaurantes. Entre los diarios analizados no existen diferencias reseñables. Los titulares de los textos de opinión publicados ese mes son en su mayoría apelativos y expresivos, y destacan la polémica, por ejemplo: "Liberados por el humo" (El País), "El camello hipócrita" (El Mundo), "Despotismo ilustrado" $(A B C)$, "Y venga marear la perdiz" (La Vanguardia) y "El castigo de la libertad" (La Razón).

Tras la entrada en vigor de la ley antitabaco, los primeros días predominan los titulares interpretativos sobre los informativos, también desde un punto de vista negativo: "Humo furtivo hasta en la UCI" (El País), "Al juez por fumar y liarla en el hospital" (El Mundo), "Guerrilla y resistencia" $(A B C)$, "A la caza del humo y colillas en el bar" (La Vanguardia), "La 'intifada' del tabaco" (La Razón). En los textos de opinión encontramos titulares como "¿Quién nos quita ahora la mala leche?" (El País), "El placer y la libertad" (El Mundo), "La rebelión" $(A B C)$, "Fumarse a los demás" (La Vanguardia), "Tabaco y caza de brujas" (La Razón). En todos los periódicos se enfoca el tema de una manera tremendista, al destacar en titulares términos más propios de una situación de excepción que de la aplicación de una norma de salud pública.

En las semanas y meses posteriores a la aprobación, en todos los diarios siguen prevaleciendo los titulares interpretativos sobre los informativos. Por un lado, destacan altercados e insumisiones de algunos hosteleros a la ley, con titulares como "El local es mío; quien quiere fuma" (El País), "Aquí se va a seguir fumando" (El Mundo), "Rebelión en Marbella" ( $A B C$ ), "Sólo acataré la ley si lo dice el juez" (La Vanguardia) y "El dueño de un local fue agredido tras pedir a un cliente que apagase el cigarro" (La Razón). A pesar de ser casos aislados, todos los periódicos recogen estos hechos a través de sus textos de opinión o en las páginas dedicadas a la información, distorsionando y amplificando su magnitud.

Por otro lado, la mayoría de los diarios subrayan en sus titulares los perjuicios económicos de la ley para la hostelería y para la economía en general, tal y como muestran estos ejemplos: "Los hosteleros exigirán que les reembolsen las peceras"(El País), "Huelga por el tabaco" (El Mundo); "Los ingresos de la hostelería caen un 60\% con la ley del tabaco" $(A B C)$, "Solo toman café y se van" (La Vanguardia), "La ley antitabaco "mata' los ingresos de la hostelería" (La Razón). Teniendo en cuenta que España se encuentra sumergida en una importante crisis económica, este tipo de titulares que inciden en las supuestas consecuencias negativas de la aplicación de la ley crean inquietud en los receptores.

Además, los titulares relacionados con las denuncias por no respetar la ley se difunden tanto en los textos de opinión como en los textos de información de todos los diarios: "Malos humos" (El País), "Ahora, persecución a los fumadores" (El Mundo), "Chivatos y acusicas" $(A B C)$, "Denunciar al fumador" (La Vanguardia), "Tabaco e integrismo" (La Razón). La mayor parte de los titulares utilizan términos peyorativos para referirse a las denuncias por incumplimiento de la ley. 
Es destacable que tanto gran parte de estos titulares interpretativos como de aquellos que son más informativos han resaltado los aspectos negativos de la ley antitabaco. Así, se ha ofrecido una un punto de vista contrario a la norma, que ha contribuido a aumentar la visión negativa de la población sobre las restricciones al humo del tabaco.

\subsection{Tema central}

A la hora de definir el encuadre temático predominante en cada pieza informativa, hemos dividido los temas centrales de cada texto en función de dos tipos de valoración: a favor o en contra de la ley. Para determinar cuál es el tema que destaca sobre los demás, hemos tenido en cuenta los temas destacados en los elementos de titulación y el espacio dedicado dentro de la pieza a cada tema.

El análisis de los encuadres temáticos ha puesto de manifiesto el predominio de aquellos que enfatizan aspectos negativos de la ley antitabaco (57,6\%), frente a los que destacan los beneficios que conlleva (42,5\%). Concretamente, los dos encuadres más utilizados son el que vincula la ley con conflictos y tensiones en la sociedad y el que destaca los perjuicios económicos que acarreará la norma. En la siguiente tabla vemos los porcentajes obtenidos por cada uno de los encuadres utilizados:

Tabla 2.- Encuadres temáticos destacados

\begin{tabular}{|c|l|r|r|}
\hline \multirow{4}{*}{ Enfoques } & \multicolumn{1}{|c|}{ Encuadre temático } & $\begin{array}{c}\mathbf{N}^{\mathbf{0}} \mathbf{d e} \\
\text { textos }\end{array}$ & \multicolumn{1}{c|}{$\%$} \\
\hline \multirow{4}{*}{$\begin{array}{c}\text { NEGATIVOS } \\
\text { (contra la ley) } \\
57,6 \%\end{array}$} & Causa conflictos y tensiones & 45 & $16,7 \%$ \\
\cline { 2 - 4 } & Perjuicios económicos & 44 & $16,4 \%$ \\
\cline { 2 - 4 } & Asunto de libertades & 28 & $10,4 \%$ \\
\cline { 2 - 4 } & Contra los derechos de los fumadores & 19 & $7,1 \%$ \\
\cline { 2 - 4 } & La ley no se cumple & 10 & $3,7 \%$ \\
\cline { 2 - 4 } & Enmiendas a la prohibición total & 6 & $2,2 \%$ \\
\cline { 2 - 4 } & Otros, en contra & 3 & $1,1 \%$ \\
\hline \multirow{4}{*}{$\begin{array}{c}\text { POSITIVOS favor de la ley) } \\
42,5 \%\end{array}$} & Defensa de la prohibición total & 30 & $11,2 \%$ \\
\cline { 2 - 4 } & Beneficios para la salud & 25 & $9,3 \%$ \\
\cline { 2 - 4 } & Cumplimiento generalizado de la ley & 22 & $8,2 \%$ \\
\cline { 2 - 4 } & Defensa derechos de no fumadores & 15 & $5,6 \%$ \\
\cline { 2 - 4 } & Adicción peligrosa contra la que luchar & 14 & $5,2 \%$ \\
\cline { 2 - 4 } & La ley no traerá perjuicios económicos & 3 & $1,1 \%$ \\
\cline { 2 - 4 } & Otros, a favor & 5 & $1,9 \%$ \\
\hline
\end{tabular}

Según diarios, El País dedica un $67,4 \%$ de las piezas sobre la ley antitabaco a destacar aspectos positivos de la misma, mientras que en un $32 \%$ se subrayan aspectos negativos. El encuadre más utilizado es el que se refiere a los beneficios para la salud que supone la nueva ley, destacado en un $20,9 \%$ de las piezas sobre el tema. En segundo lugar, se sitúa la idea del cumplimiento generalizado de la ley (16,3\%). Ambos enfoques indican un posicionamiento del medio a favor de la ley. En tercer lugar aparecen empatados tres encuadres, con un porcentaje del 11,6\% de los textos. Dos de ellos destacan también los aspectos positivos de la ley: defensa de los derechos de los no fumadores, por un lado, y defensa de la prohibición total de fumar, por otro. El 
otro enfoque acentúa los perjuicios económicos que, previsiblemente, acarreará la ley en el sector de la hostelería. En sexto lugar se sitúa la idea de que la ley es causa de conflictos y tensiones $(9,3 \%)$, seguida de los encuadres que destacan que la ley no traerá perjuicios económicos $(7 \%)$, y que supone un atentado contra los derechos de los fumadores (4,7\%). En último lugar se sitúan con el mismo porcentaje $(2,3 \%)$ tres encuadres que subrayan aspectos negativos de la norma: presentarla como un asunto de libertades individuales, recurrirla ante los tribunales y dar la imagen de que no se cumple.

El Mundo encuadra un $46,7 \%$ de sus textos a favor de la ley y un $53,3 \%$ en contra. El encuadre temático que más resalta este periódico resalta aspectos negativos: la ley es causa de conflictos y tensiones $(16,7 \%)$. En segundo lugar aparece el encuadre que se refiere al cumplimiento generalizado de la ley $(13,3 \%)$. En tercer lugar, con un porcentaje del $10 \%$ de los textos, se sitúan tres encuadres que van en contra de la ley (atentado a los derechos de los fumadores, perjuicios económicos y asunto de libertades) y dos que van a favor de ella (el tabaco como adicción peligrosa contra la que luchar y defensa de los derechos de los fumadores). Los encuadres menos utilizados, con un $6,7 \%$ sobre el total de piezas de este diario, son la idea de que la ley no se cumple, la ley como beneficiosa para la salud de la población y "Otros encuadres a favor de la ley".

Un $18,7 \%$ de los textos de $A B C$ incluyen encuadres a favor de la ley, mientras que un $81,4 \%$ se decantan en contra de la ley. Los cuatro temas que más sobresalen en este diario corresponden a encuadres que se refieren a los aspectos negativos de la ley: traerá perjuicios económicos $(25,4 \%)$, es un atentado contra los derechos de los fumadores $(20,3 \%)$, es un asunto de libertades $(20,3 \%)$ y transmitir la imagen de que no se cumple $(8,5 \%)$. El quinto encuadre es el que alude al tabaco como adicción peligrosa contra la que luchar $(6,8 \%)$, seguido del de la ley como causa de conflictos y tensiones $(5,1 \%)$, del de los beneficios para la salud que supondrá $(5,1 \%)$, del que se refiere al cumplimiento generalizado de la ley $(3,4 \%)$, de la presentación de enmiendas a la prohibición total $(1,7 \%)$, de la defensa de los derechos de los no fumadores $(1,7 \%)$ y de la defensa de la prohibición total de fumar $(1,7 \%)$.

La Vanguardia encuadra un 59,5\% de sus piezas a favor de la ley y un $40,5 \%$ en contra de la ley. El encuadre que más utiliza este diario es uno que destaca aspectos negativos de la ley: que es causa de conflictos y tensiones en la sociedad, mayoritario en un $27,8 \%$ de sus piezas. Le siguen otros encuadres a favor de la ley: defensa de la prohibición total de fumar $(25,3 \%)$, beneficios para la salud $(11,4 \%)$, defensa de los derechos de los no fumadores $(8,9 \%)$ y cumplimiento generalizado de la ley $(7,6 \%)$. En sexto lugar aparece el encuadre de los perjuicios económicos derivados de la ley $(6,3 \%)$, seguido de la idea del tabaco como adicción peligrosa contra la que luchar $(3,8 \%)$, de la ley como asunto de libertades $(3,8 \%)$ y de la presentación de enmiendas a la prohibición total de fumar $(1,3 \%)$. También hay un $2,5 \%$ de textos clasificados como "Otros encuadres, a favor de la ley" y un 1,3\% dentro de "Otros encuadres, en contra".

La Razón dedica un 22,4\% de las piezas sobre la ley antitabaco a subrayar aspectos positivos de la misma, mientras que en un $77,6 \%$ se destacan aspectos negativos. 
El encuadre que más sobresale en este diario es el que se refiere a los perjuicios económicos que acarreará en el sector hostelero $(27,6 \%)$, seguido de que la ley es causa de conflictos y tensiones (19\%) y del encuadre referido a la ley como asunto de libertades $(15,5 \%)$. En cuarto lugar, aparecen tres encuadres con un porcentaje del 6,9 de los textos: enmiendas a la prohibición total de fumar, el tabaco como adicción peligrosa contra la que luchar y defensa de la prohibición total. Después se sitúa el encuadre que destaca que la ley se está cumpliendo de forma mayoritaria $(5,2 \%)$ y en último lugar aparecen tres encuadres que comparten el 3,4\% de las piezas: la ley atenta contra los derechos de los fumadores, la ley no se cumple y su aplicación traerá beneficios para la salud. Por último, aparece un $1,7 \%$ de los textos que han sido clasificados como "Otros encuadres, en contra de la ley".

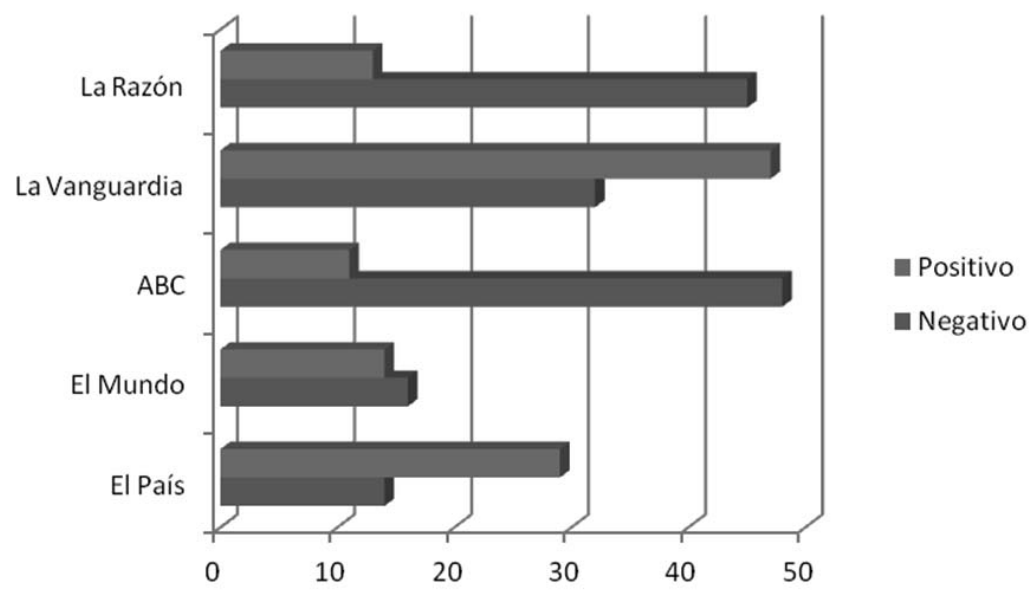

Gráfico 3.- Encuadres temáticos según diarios

\subsection{Fuentes de información}

Se han detectado un total de 578 fuentes de información mencionadas en los textos sobre la ley del tabaco. Las más utilizadas son las que pertenecen al sector de la hostelería $(27,2 \%)$, principalmente federaciones y asociaciones de hosteleros o de empresarios y hosteleros individuales. En segundo lugar, aparecen las fuentes institucionales (23,9\%), entre las que destacan el Ministerio de Sanidad y portavoces de partidos políticos. A continuación, figuran las fuentes que provienen de la sociedad civil $(18,7 \%)$, dentro de las cuales las más empleadas son asociaciones ciudadanas de fumadores y de no fumadores- y ciudadanos individuales. Les siguen a poca distancia los expertos sanitarios (16,8\%), entre los que destacan representantes de organizaciones médicas o sanitarias. En cuarto lugar encontramos a expertos en otros ámbitos $(6,1 \%)$, sobre todo directores de teatro y catedráticos de universidad. Por último, hay otras fuentes que se mencionan en menor medida: medios de comunicación $(2,9 \%)$, agencias de comunicación $(2,4 \%)$, empresas tabaqueras $(0,7 \%)$ y otras fuentes $(1,4 \%)$. 
Estos datos muestran un cierto equilibrio entre los cuatro tipos de fuentes mayoritarias (hosteleros, instituciones, sanitarios y ciudadanos), lo que en un principio indica que los diarios han intentado dar voz a todos los actores implicados en el proceso de implantación de la ley.

Llama la atención la poca presencia de las empresas tabaqueras como fuente de información, dato que corrobora las conclusiones de Granero, Villalbí y Gallego de que el abanico de actores protabaco es muy amplio e intersectorial y no se limita a las tabaqueras, las cuales utilizan otros actores (como el Club de Fumadores por la Tolerancia, hosteleros o algunos partidos políticos) para que defiendan sus intereses (Granero, Gallego, 2004: 379).

También es llamativa la escasa mención a las agencias de noticias como fuente de información. Si bien, tenemos que tener en cuenta que en la práctica periodística es habitual que se utilice información enviada por agencias e -incluso- citas de fuentes procedentes de teletipos en textos firmados por periodistas sin hacer ninguna alusión a la agencia autora, tal y como ha demostrado Gelado (2009: 268-269).

\subsection{Información gráfica}

La cobertura de la aprobación de la ley antitabaco en los seis meses analizados utiliza un total de 175 piezas gráficas, de las cuales la inmensa mayoría son fotografías (156), seguidas a gran distancia de dibujos (8), infográficos (6) y gráficos (5). Por diarios, $A B C$ es el que más imágenes publica con diferencia (58), seguido por La Razón (48), La Vanguardia (31), El País (25) y El Mundo (13). Debido al gran número de textos de opinión que abordan el tema, más de la mitad de los textos analizados no van acompañados de elementos gráficos.

La mayoría de las fotografías -no así los gráficos e infografías, que son explicativos y clarificadores de resultados de encuestas, cifras de población fumadora, datos de enfermedades relacionadas con el tabaco, etc.- representan imágenes que tratan de reflejar situaciones habituales: carteles que anuncian la entrada en vigor de la ley y personas fumando en la calle.

Hay que señalar que todos los diarios, excepto El País, publicaron el 5 de enero la misma fotografía, donde aparece un primer plano de los 16 puntos de sutura en la frente del dueño de una bolera, después de que un cliente le agrediese por pedirle que no fumara. La fotografía llama la atención y busca sobre todo tocar la sensibilidad humana porque muestra detalladamente la brecha, los restos de sangre y el hilo negro de los puntos.

Los diarios $A B C$ y La Razón han utilizado repetidamente fotografías que recogen primeros planos de ceniceros atestados de colillas e imágenes de las protestas de los hosteleros indignados por la aplicación de la ley antitabaco.

La mayoría de las fotografías pertenecen al diario que las difunde y cumplen la función de acompañamiento a los textos que van unidas, sin aportarles apenas valor informativo o explicativo. Las instantáneas refuerzan el mensaje que ha predominado en los textos y que enfatiza los efectos negativos que la norma ha supuesto para la población fumadora y para la hostelería.

El diario La Razón es el único que utiliza infografías para acompañar sus textos. Un $10,3 \%$ de las imágenes que publica en las noticias sobre la ley del tabaco corres- 
ponden a infografías, que es una herramienta más explicativa y analítica que otros tipos de imágenes, y, por tanto, más apropiada para la divulgación de las noticias sobre salud, ya que las impregna "de una capacidad pedagógica y educativa que trasciende a las noticias tradicionales" (Moreno, 2010: 328).

\section{Conclusiones}

El análisis pone de manifiesto que la ley antitabaco ha sido tratada por la prensa española desde la perspectiva de un periodismo de opinión. Los diarios dedican al tema un amplio porcentaje de textos opinativos, entre los que destacan las columnas, las cartas al director y los editoriales. Los autores de esos textos son, en su mayoría, redactores o colaboradores habituales de los periódicos -en el caso de las columnas y los editoriales- y lectores -en el caso de las cartas-. En menor medida se da la voz a los expertos -que firman sobre todo artículos- que son los que pueden aportar un punto de vista más riguroso sobre el asunto.

Concluimos, pues, que la prensa ha aprovechado el clima de debate que la ley había generado entre la ciudadanía antes de su aprobación y se ha convertido en un foro de debate sobre las consecuencias de esa aprobación. Foro en el que se transmite, principalmente, el punto de vista de los diarios y el punto de vista de la población.

Informativamente hablando, los diarios no dedican al tema un lugar preferente, ni en sus portadas -son muy pocos los días en los que la ley aparece en primera páginani en su interior -la mayor parte de los textos se ubican en páginas pares-. No es un tema con un amplio contenido informativo, más allá del propio texto de la norma, por lo que la mayor parte de las informaciones son de formato reducido, limitadas a los datos objetivos y con poco margen para la explicación y la profundización. Sin embargo, los diarios han cuidado la calidad de las informaciones, por el hecho de que en su mayoría han sido escritas por periodistas especializados en salud o en temas sociales, y por la variedad de fuentes de información utilizadas, que representan a todos los actores implicados en el proceso de implantación de la ley.

Los periódicos ofrecen un encuadre de los textos en contra de la ley del tabaco, ya que enfatizan los aspectos negativos que puede acarrear la norma sobre sus efectos positivos. Los encuadres negativos que priman son dos: por un lado, el que asocia la ley a conflictos y tensiones entre los ciudadanos, y por otro, el que subraya los perjuicios económicos de la ley. En particular, $A B C$ y La Razón son los dos diarios de los cinco analizados que muestran un encuadre más recurrente en contra de la ley. La diferencia respecto al resto de publicaciones llama poderosamente la atención, puesto que ambos encuadran más del $75 \%$ de sus textos en contra de la ley. El Mundo también se posiciona en contra de la ley pero de una manera más equilibrada, con un $53,3 \%$ de sus textos. Por su parte, El País y La Vanguardia ofrecen un enfoque favorable de la ley.

Por tanto, deducimos que los medios han destacado principalmente las reacciones más negativas que la norma ha provocado entre la ciudadanía. Como consecuencia, se ha transmitido el mensaje de que la mayoría de la sociedad no veía con buenos ojos la ley antitabaco. Por el contrario, el punto de vista médico según el cual fumar es una conducta perjudicial para la salud ha quedado en un segundo plano en el tratamiento que los diarios han hecho de la norma. 
Si tenemos en cuenta la capacidad que tienen los medios de comunicación de influir en los comportamientos de los receptores, hay evidencias de que este mensaje contrario a la prohibición de fumar ha condicionado la manera en que la ciudadanía ha recibido la aprobación de la ley en un sentido negativo desde el punto de vista de la concienciación social en contra del consumo del tabaco.

\section{Referencias}

ASOCIACIÓN NACIONAL DE INFORMADORES DE LA SALUD (ANIS) (2011):

"España, campo de pruebas de las tabaqueras", en Documentos Anisalud, no 1 : http://www.actasanitaria.com/fileset/doc_61864_FICHERO_NOTICIA_20651.pdf [fecha de consulta: 13 de abril de 2012]

ARMENTIA, José Ignacio y CAMINOS, José María (2009): Redacción informativa en prensa. Barcelona, Ariel.

BÁEZ, Juan (2007): Investigación cualitativa. Pozuelo de Alarcón, ESIC.

BARRUECO, Miguel (2003): “Estrategias de prevención”, en BARRUECO, Miguel et al.: Manual de Prevención y Tratamiento del Tabaquismo. Madrid, ERGON, pp. 69-106.

CAMACHO, Idoia (2009): "La 'Gripe A' en la prensa española". Revista Latina de Comunicación Social, 64. La Laguna (Tenerife), Universidad de La Laguna, pp. 827-843: http://www.revistalatinacs.org/09/art/865_Bilbao/RLCS_art865.pdf [fecha de consulta: 19 de abril de 2012].

GELADO, Roberto (2009): "La dependencia de la prensa española hacia las agencias de noticias". Comunicación y Sociedad, vol. XXII, $n^{\circ}$ 2. Pamplona, Universidad de Navarra, pp. 243-275.

GERMÁN, Isabel (2009): "Análisis de la legislación relacionada con el tabaco. Implicaciones de carácter práctico en su aplicación", en OBSERVATORIO VASCO DE DROGODEPENDENCIAS: Políticas y legislación en materia de tabaco. Vitoria-Gasteiz, Servicio Central de Publicaciones del Gobierno Vasco, pp. 71-153.

GIMÉNEZ, Pilar y BERGANZA, María Rosa (2009): Género y medios de comunicación: un análisis desde la objetividad y la teoría del framing. Madrid, Fragua.

GRANERO, Lluís et al. (2004): “¿Quién se opone a la prevención? Un mapa de los actores pro tabaco en España". Gaceta Sanitaria, vol. 18, n 5, septiembre-octubre. Barcelona, Elsevier, pp. 374-379.

HERNÁNDEZ, Laura (2011): “Análisis de los contenidos sociosanitarios en la prensa local”. Revista Española de Comunicación en Salud, vol. 2, n ${ }^{\circ}$. Málaga, Asociación Española de Comunicación Sanitaria, pp. 24-31.

IGARTUA, Juan José; MUÑIZ, Carlos et al. (2007): "El tratamiento informativo de la inmigración en los medios de comunicación españoles. Un análisis de contenido desde la Teoría del Framing". Estudios sobre el Mensaje Periodístico, Vol. 13. Madrid, Servicio de Publicaciones de la Universidad Complutense, pp. 91-110. 
LLAGUNO-AGUILAR et al. (2008): "Análisis de la cobertura de tema de tabaco en medios impresos mexicanos". Salud Pública de México, no 50, supl 3. Cuernavaca, Instituto Nacional de Salud Pública, pp. 348-354.

MARCUS, Stephen (2008): El rol de los medios de comunicación en la promoción y en la reducción del consumo de tabaco. Monografía 19 del Instituto Nacional del Cáncer sobre el control del tabaco. Baltimore, Instituto Nacional del Cáncer de EE.UU.

MORENO, Pastora (2010): "Periodismo biomédico, nuevos contenidos mediáticos". Estudios sobre el mensaje periodístico, vol. 16. Madrid, Servicio de Publicaciones de la Universidad Complutense, pp. 319-330.

SÁDABA, Teresa (2008): Framing: el encuadre de las noticias. El binomio terrorismo-medios. Buenos Aires, La Crujía.

SERRANO, María Soledad y ROJO, Blas (2004): "Historia y epidemiología del tabaquismo", en JIMÉNEZ, Carlos y SOLANO, Segismundo: Tabaquismo. Monografías de la Sociedad Madrileña de Neumología y Cirugía Torácica. Madrid, NEUMOMADRID, pp. 9-25.

TERAMO, María Teresa y VENINO, Teresita María (2003): "Medición de la subjetividad en la prensa escrita". Comunicación y Sociedad, vol. XVI, n 1 . Pamplona, Universidad de Navarra, pp. 139-155. 